\title{
Right Atrial Appendage
}

National Cancer Institute

\section{Source}

National Cancer Institute. Right Atrial Appendage. NCI Thesaurus. Code C127646.

The ear-shaped, muscular pouch of the right atrium. 